\title{
Tight junction properties of the immortalized human bronchial epithelial cell lines Calu-3 and 16HBE140-
}

\author{
H. Wan*, H.L. Winton*, C. Soeller*, G.A. Stewart ${ }^{\#}$, P.J. Thompson ${ }^{\# \#, ~ D . C . ~ G r u e n e r t ~}{ }^{+}$, \\ M.B. Cannell*, D.R. Garrod ${ }^{++}$, C. Robinson*
}

Tight junction properties of the immortalized human bronchial epithelial cell lines Calu-3 and 16HBE14o-. H. Wan, H.L. Winton, C. Soeller, G.A. Stewart, P.J. Thompson, D.C. Gruenert, M.B. Cannell, D.R. Garrod, C. Robinson. CERS Journals Ltd 2000.

ABSTRACT: Tight junctions (TJs) make a vital contribution to the barrier properties of the airway lining. Opening of TJs, or their frank cleavage, is suspected as a pathophysiological event in the lung, but research into the cellular and molecular mechanisms involved has been impeded by technical limitations of available experimental models. The authors have compared the properties of two epithelial cell lines derived from bronchial epithelium to explore whether these cell lines could constitute appropriate tools for the study of $\mathrm{TJ}$ regulation in bronchial epithelium.

Investigations of TJs in $16 \mathrm{HBE} 140$ - cells and Calu-3 cells were made by fluorescent antibody labelling in conjunction with wide-field, confocal or 2-photon molecular excitation microscopy (2PMEM). The presence of TJ proteins was confirmed by immunoblotting and functional properties of the monolayers were studied by measurements of transepithelial electrical resistance and mannitol permeability.

Cells of both lines formed confluent monolayers in which the cells expressed the TJ proteins occludin and $\mathrm{ZO}-1$ in continuous circumferential patterns suggestive of functional TJs. This interpretation was supported by the development of transepithelial electrical resistances and of low paracellular permeability to solutes. Within the limits of resolution offered by 2 PMEM, occludin and ZO-1 appeared to colocalize at TJs.

These studies suggest that the 16HBE140- cells and Calu-3 cell lines are potentially useful in vitro models to study how tight junction opening or cleavage changes the functional barrier properties of bronchial epithelium. Eur Respir J 2000; 15: 1058-1068.
*Dept of Pharmacology \& Clinical Pharmacology, St George's Hospital Medical School, London, UK. Depts of "Microbiology and ${ }^{\# \#}$ Medicine, University of Western Australia, Queen Elizabeth II Medical Centre, Perth, Australia. ${ }^{+}$UCSF Gene Therapy Core Centre, Dept of Laboratory Medicine, University of California, San Francisco, CA, USA. ${ }^{++}$School of Biological Sciences, University of Manchester, Manchester, UK.

Correspondence: C. Robinson, Dept of Pharmacology \& Clinical Pharmacology, St. George's Hospital Medical School, Cranmer Terrace, London, SW17 0RE, UK. Fax: 442087250685

Keywords: Airway epithelium, occludin permeability, tight junction, zonulae adherentes, $\mathrm{ZO}-1$

Received: December 311998

Accepted after revision November 51999

This study was supported by the National Asthma Campaign (UK).
The integrity of the barrier formed by the epithelial lining of the airways is dependent upon the continuity of the superficial layer of columnar cells and the effectiveness of the adhesions formed between neighbouring cells and with the biomatrix [1]. Of the lateral intercellular adhesions, tight junctions (TJs) define the physiological interface between functionally distinct apical and basolateral plasma membrane domains. Furthermore, they govern the permeability of the airway lining by regulating access to the paracellular spaces between columnar cells [2-4]. TJs are formed from macromolecular complexes of proteins and have a continuous distribution around the apical perimeter of epithelial cells. TJ proteins such as ZO-1, ZO-2, ZO-3, cingulin, symplekin and AF-6 are localized to the cytoplasmic face of the junction [3-7] and do not participate directly in the formation of an intercellular seal at TJs. However, as some of these proteins are anchored to the cytoskeleton, they may be able to regulate $\mathrm{TJ}$ function indirectly. In contrast to the above, occludins and claudins are membrane-spanning proteins that are considered to seal TJs by creating homotypic interactions with neighbouring cells [8-11].

The paracellular permeability properties of the epithelial barrier thus depend upon proteins that have extracellular domains. This dependency raises the possibility that the effectiveness of TJs may be influenced by external factors that perturb protein structure/function. Perturbation of the exogenous domains of TJs may have pathophysiological consequences. For example, it has been suggested that allergic sensitization might be facilitated by peptidase allergens that lead to cleavage of the extracellular domains of TJs $[12,13]$. It has also been speculated that activated eosinophils cause the bronchial epithelium to become hyperfragile by promoting cleavage of both lateral and basal adhesions of epithelial cells [14, 15].

In order to define the importance of intercellular junctions in both physiological and pathophysiological events in the airway lining it is necessary to characterize models that are appropriate for such investigations. For detailed studies of the cellular and molecular mechanisms involved in the regulation of airway TJs, it is desirable to undertake these investigations in cultured cells. Unfortunately, primary cultures of epithelial cells from lung tissue have the disadvantage of being derived from heterogeneous sources and exhibit both an acute phenotypic instability and lack of longevity in culture. A number of immortalized cell lines have been established from airway mucosa and some of these have been used to investigate responses following a 
miscellany of experimental treatments. Whilst some of these cell lines (e.g. A549 and BEAS-2B) have been utilized for biochemical investigations, most epithelial cell cultures derived from lung are unsuited to investigations of the events concerned with alterations in epithelial barrier properties. This unsuitability arises because many of the immortalized epithelial cell lines do not correctly express crucial components of intercellular junctions (unpublished data) [16]. In this paper, the authors describe the intercellular junctions and barrier properties of two human bronchial epithelial cell lines that offer the potential to be useful paradigms of the lateral cell adhesions of human airway epithelium.

\section{Methods}

\section{Cell culture}

16HBE14o- cells, Calu-3 cells and Madin-Darby canine kidney (MDCK) epithelial cells were cultured as previously described in full [17]. In the present studies, MDCK cells were used as an experimental reference because of their highly characterized intercellular adhesions. 16HBE14o- cells have the characteristics of superficial epithelial cells and were originally derived by viral transformation of cells dissociated from human bronchial epithelium [17]. Previous phenotyping of Calu-3 cells, which are derived from an adenocarcinoma, suggests that they have seromucous attributes [18].

In experiments to examine the breakdown and formation of TJs, cells were seeded at confluent density into $60-\mathrm{mm}$ Petri dishes containing glass coverslips. Cells were allowed to adhere in normal culture medium for $5 \mathrm{~h}$ and then washed and placed in culture medium containing $5 \mathrm{mM}$ ethylene glycol tetra-acetic acid (EGTA) to "down switch" extracellular $\mathrm{Ca}^{2+}$. Three days after plating, cells were washed in fresh medium and extracellular $\mathrm{Ca}^{2+}$ restored to normal levels ("up switch"). At various times after the "up switch" of $\mathrm{Ca}^{2+}$, cells were fixed and their TJ proteins examined by fluorescent antibody labelling.

\section{Measurement of permeability}

Measurements of $\left[{ }^{14} \mathrm{C}\right]$-mannitol clearance and permeability were performed exactly as described previously [19]. Experiments were conducted in confluent monolayers of epithelial cells which had been propagated on ultrathin undercoats of ungelled Matrigel in Costar Transwells (Corning-Costar Ltd., High Wycombe, Buckinghamshire, UK). All cell lines were seeded at densities of $5 \times 10^{5}$ cells $\cdot$ insert $^{-1}$.

\section{Measurement of transepithelial electrical resistance}

Transepithethial electrical resistance (TER) was measured in Endohm ${ }^{\mathrm{TM}}$ tissue resistance measurement chambers (World Precision Instruments, Inc., Sarasota, FL, USA) by applying a $\pm 20-\mu \mathrm{A}$ square wave alternating current across the monolayers at $12.5 \mathrm{~Hz}$. The values of TER cited in this manuscript were made with $5 \mathrm{~mL}$ medium in the outer well and $0.1 \mathrm{~mL}$ medium in the Transwell insert. The resistance of cell-free Transwell inserts was measured for control purposes and proved to be minimal $\left(<1 \Omega \cdot \mathrm{cm}^{2}\right)$.
Cellular staining by fluorescent probes and indirect immunocytochemistry

To determine the extent of cell coverage over Transwell inserts and the viability of cells at any time point during culture, sample inserts were selected at random and stained with ethidium bromide and acridine orange (Merck Ltd., Lutterworth, Leicestershire, UK). The cells were rinsed twice with phosphate-buffered saline (PBS) and $100 \mu \mathrm{L}$ of acridine orange and $100 \mu \mathrm{L}$ ethidium bromide $\left(1 \mathrm{mg} \cdot \mathrm{mL}^{-1}\right.$ for each) added under subdued illumination. The cells were immediately examined by fluorescence microscopy using a Zeiss Axiovert 10 microscope (Carl Zeiss Ltd., Welwyn Garden city, Hertfordshire, UK) with blue/green excitation filter sets.

Intercellular junctions were examined by fluorescent antibody labelling using monoclonal antibodies (mAbs) for occludin, E-cadherin, and desmoplakin as described elsewhere [16]. The mAbs used were rat antioccludin (MOC37; a kind gift of S. Tsukita, Kyoto University, Kyoto, Japan) [20], rat anti-E-cadherin (DECMA-1; Sigma, Poole, Dorset, UK) [21] and mouse antidesmoplakin $(11-5 F)$ [22]. In human cells ZO-1 was labelled using a rabbit polyclonal antibody (a kind gift from T. Fleming, University of Southampton, Southampton, UK), and in MDCK cells with rat mAb R40.76 (a kind gift from B. Stevenson, University of Alberta, Edmonton, Alberta, Canada) [23]. $\beta$-Catenin was labelled using a rabbit polyclonal antibody (Sigma). Antibodies were diluted for use in $\mathrm{PBS} / 0.2 \%$ volume $(\mathrm{v}) / \mathrm{v}$ Tween-20 containing $10 \% \mathrm{v} / \mathrm{v}$ nonimmune serum. All of the cells used in the studies of intercellular junctions were fixed in ice-cold methanol and blocked in $10 \% \mathrm{v} / \mathrm{v}$ nonimmune serum before primary antibody binding. For ZO-1 and E-cadherin staining, modified CSK buffer (composition: $\mathrm{NaCl} 50 \mathrm{mM}$, sucrose 3,000 mM, piperazine- $N, N^{\prime}$-bis [2-ethanesulphonic acid] (PIPES; pH 6.8) $10 \mathrm{mM}, \mathrm{MgCl}_{2} 3 \mathrm{mM}, 0.5 \% \mathrm{v} / \mathrm{v}$ Triton X-100, 4-(2-aminoethyl)-benzenesulphonyl fluoride hydrochloride $1.2 \mathrm{mM}$ ) was applied before fixation to remove staining not associated with cytoskeletal components. Indirect immunocytochemistry was performed in specimens labelled with one or two primary antibodies depending on the experiment. For single-antibody labelling studies the affinity-purified secondary immunoglobulin $\mathrm{G}$ was conjugated with fluorescein isothiocyanate (FITC). In dual labelling studies, an appropriately paired combination of affinity-purified, immunoabsorbed second antibodies conjugated with fluorescein dichlorotriazine (DTAF) and tetraethylrhodamine isothiocyanate (TRITC) was used (Chemicon International, Harrow, Middlesex, UK). F-actin was labelled using rhodamine phalloidin (Cambridge Bioscience, Cambridge, UK) in cells that had been fixed in $3.7 \% \mathrm{v} / \mathrm{v}$ formaldehyde and permeabilized in $0.1 \% \mathrm{v} / \mathrm{v}$ Triton $\mathrm{X}-100$.

Epifluorescence microscopy was performed using a Zeiss Axiovert 10 microscope with oil immersion objectives (Carl Zeiss Ltd.). Fluorescence excitation was at 450$490 \mathrm{~nm}$ and emission at $>520 \mathrm{~nm}$ for FITC or DTAF, and $546 />590 \mathrm{~nm}$ for TRITC or rhodamine phalloidin. Photographic documentation of results was made using a Contax 167MT camera (Kyocera Yaschica UK Ltd., Reading, UK) and Kodak TMAX 400 film for black and white prints (Kodak, Hemel Hempstead, UK). Single-photon confocal 
microscopy was performed using a Zeiss LSM510 microscope (Carl Zeiss Ltd.). Image stacks from confocal microscopy were processed entirely in the digital domain.

2-Photon molecular excitation microscopy (2PMEM) of fixed cell preparations was performed on a modified Zeiss LSM410 microscope (Carl Zeiss Ltd.) with excitation at $810 \mathrm{~nm}$ from a Ti:sapphire modelocked laser (Coherent Laser Group, Santa Clara, CA, USA) using pulses of 80$100 \mathrm{fs}$ duration [24]. The technique of 2PMEM limits specimen-bleaching outside the focal plane and thus enables quantitative analysis of fluorescent antibody labelling to be performed. Quantitative digital image analysis of the breaks within the TJ staining pattern was performed as fully described elsewhere [25].

\section{Immunoblotting}

Whole cell protein extracts for immunoblotting were prepared exactly as described elsewhere [25]. Nonspecific protein binding was blocked with $5 \%$ weight $(\mathrm{w}) / \mathrm{v}$ nonfat milk and $0.1 \% \mathrm{v} / \mathrm{v}$ Tween-20 in Tris-buffered saline (TBS) followed by incubation with primary antibodies diluted in TBS containing $2 \% \mathrm{w} / \mathrm{v}$ bovine serum albumin and $0.1 \% \mathrm{v} / \mathrm{v}$ Tween-20. MOC37 and R40.76 were the mAbs used to detect occludin and ZO-1 respectively in MDCK cells. Rabbit polyclonal anti-ZO-1 or antiocclu-

a)

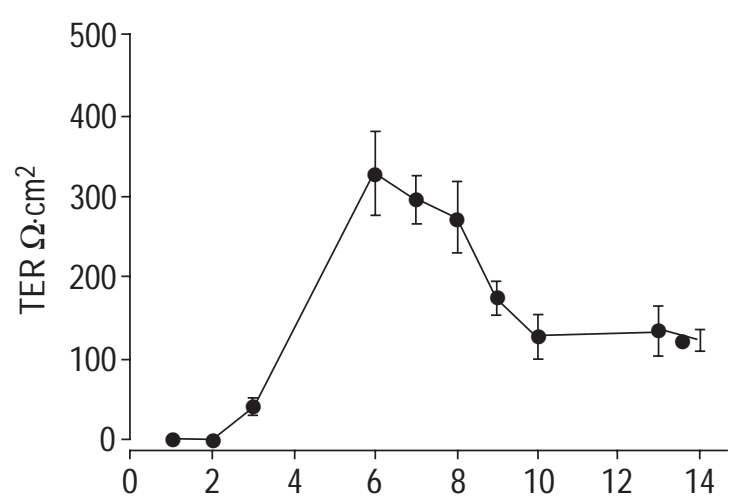

c)

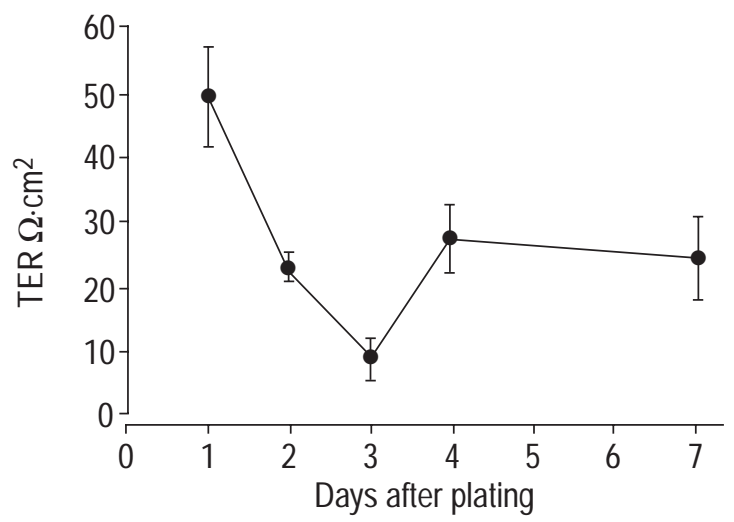

din (Zymed, Inc., San Francisco, CA, USA) were used in human airway cells. Detection was by enhanced chemiluminescence technique (Amersham Pharmacia, Little Chalfont, Buckinghamshire, UK).

\section{Results}

\section{Measurements of transepithelial electrical resistance}

Visual inspection indicated that all three of the cell lines formed tightly packed monolayers. At confluence the average cell diameters (arithmetic mean \pm SEM) were $25.4 \pm 0.7$, $26.8 \pm 0.6$ and 23.0 $\pm 0.6 \mu \mathrm{m}$ for MDCK, Calu-3 and $16 \mathrm{H}-$ BE14o- cells respectively ( $\mathrm{n}=300$ for each). Assuming the functionally essential components of TJs are expressed by each cell line, and that their cell borders are similarly tortuous, the mean cell diameters suggest that the barrier properties of monolayers formed by the three cell lines should be comparable.

Figures $1 \mathrm{a}$ and $\mathrm{b}$ show that, after plating on $0.4-\mu \mathrm{m}$ porosity Transwells, monolayers of $16 \mathrm{HBE} 14 \mathrm{o}-$ and Calu-3 cells developed increasing TER values which reached maxima of (mean \pm SEM) $327.8 \pm 51.7$ and $359.5 \pm 46.7$ $\Omega \cdot \mathrm{cm}^{2}$ respectively $(\mathrm{n}=5)$ 6-8 days after plating. Thereafter, TER declined to values of $\sim 120 \Omega \cdot \mathrm{cm}^{2}$ by day 14 . In contrast, MDCK cell monolayer TER was $50 \pm 7.5$ $\Omega \cdot \mathrm{cm}^{2}$ on day 1 after plating and then declined to an

b)

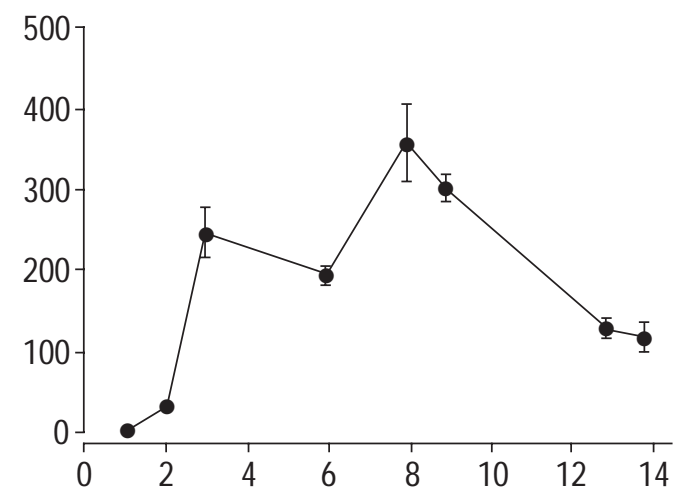

d)

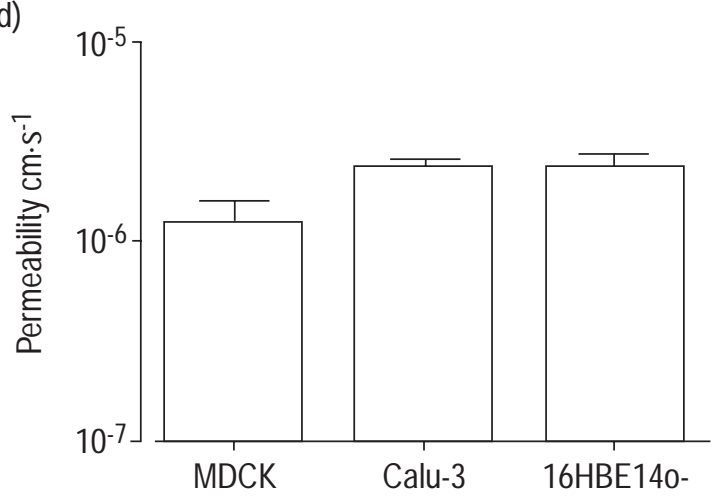

Fig. 1. - Sequential changes in transepithelial electrical resistance (TER) in epithelial monolayers following seeding into Transwell inserts. a-c) Results for monolayers of 16HBE14o-, Calu-3 and Madin-Darby canine kidney (MDCK) cells respectively. d) The permeability of the monolayers to mannitol measured 14 days after plating. Data are mean \pm SEM from 4-5 experiments. 

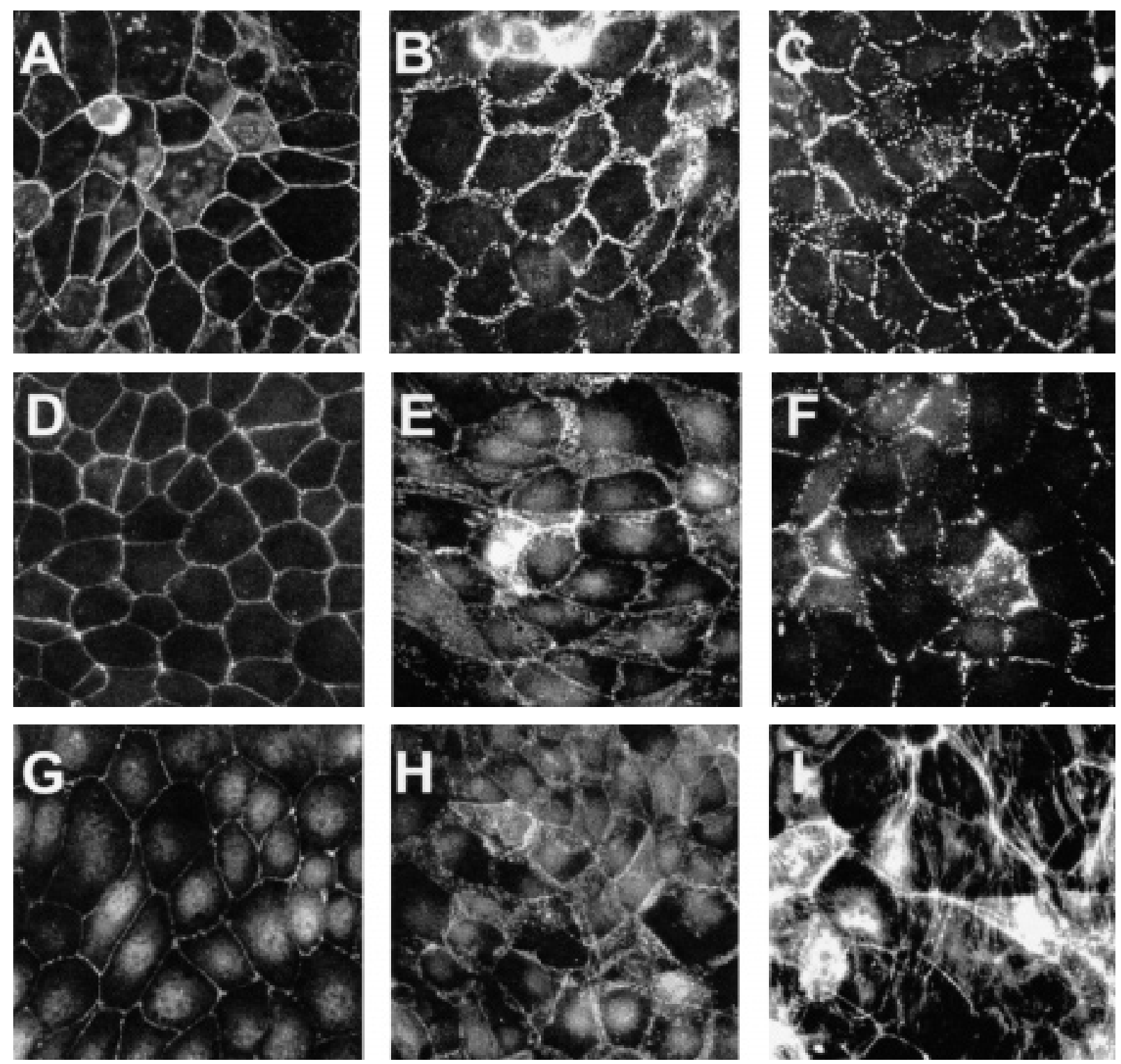

Fig. 2. - Fluorescent antibody staining of proteins associated with intercellular adhesions in the human airway epithelial cell line 16HBE14o- and their visualization by conventional epifluorescence microscopy. A-C show labelling patterns of occludin, E-cadherin and desmoplakin, respectively, without CSK buffer. D-I show labelling of occludin, E-cadherin, desmoplakin, ZO-1, $\beta$-catenin and F-actin, respectively, in cells treated with CSK buffer prior to fixation and fluorescent antibody staining.

apparent steady-state of $20-30 \Omega \cdot \mathrm{cm}^{2}$ by day 7 (fig. $1 \mathrm{c}$ ). Although the monolayers of MDCK cells had the lowest values of TER, they were nevertheless effective barriers to paracellular diffusion. The mannitol permeability coefficients measured in monolayers of 16HBE14o-, Calu-3 and MDCK cells 14 days after seeding were $2.36 \pm 0.40 \times$ $10^{-6} \mathrm{~cm} \cdot \mathrm{s}^{-1}, 2.37 \pm 0.16 \times 10^{-6} \mathrm{~cm} \cdot \mathrm{s}^{-1}$ and $1.23 \pm 0.36 \times 10^{-6}$ $\mathrm{cm} \cdot \mathrm{s}^{-1}$, respectively (fig. 1d). TER was a poor predictor of mannitol permeability as shown by comparison of the mannitol permeability coefficients measured earlier in the culture period. The permeability coefficient for mannitol measured in MDCK cell monolayers 3 days after seeding, when TER had fallen to a low value, was $0.76 \pm 0.07 \times 10^{-6}$ $\mathrm{cm} \cdot \mathrm{s}^{-1}$. In contrast, permeability coefficients of $0.31 \pm$ $0.01 \times 10^{-6} \mathrm{~cm} \cdot \mathrm{s}^{-1}$ and $1.29 \pm 0.08 \times 10^{-6} \mathrm{~cm} \cdot \mathrm{s}^{-1}$ were obtained in Calu-3 and 16HBE14o- cells when TERs of several hundred $\Omega \cdot \mathrm{cm}^{2}$ were established ( $\mathrm{n}=5$ for each cell line).

\section{Fluorescent antibody labelling of intercellular junctions}

Figures $2 \mathrm{~A}$ and $3 \mathrm{~B}$ show that confluent monolayers of 16HBE14o- and Calu-3 cells exhibited well-defined staining of the TJ protein occludin. The TJs in these cells appeared as near-continuous rings localized to the periphery of each cell. Figures 2 and 3 also reveal a welldefined ring of E-cadherin labelling that was associated with a diffuse cytoplasmic meshwork (figs. $2 \mathrm{~B}$ and $3 \mathrm{~B}$ ). Both cell lines showed ring-like immunostaining of $\beta$ catenin (figs. $2 \mathrm{H}$ and $3 \mathrm{H}$ ), an undercoat protein found to be associated with E-cadherin at adherens junctions (zonulae adherentes) in epithelia. Fluorescent antibody labelling of 

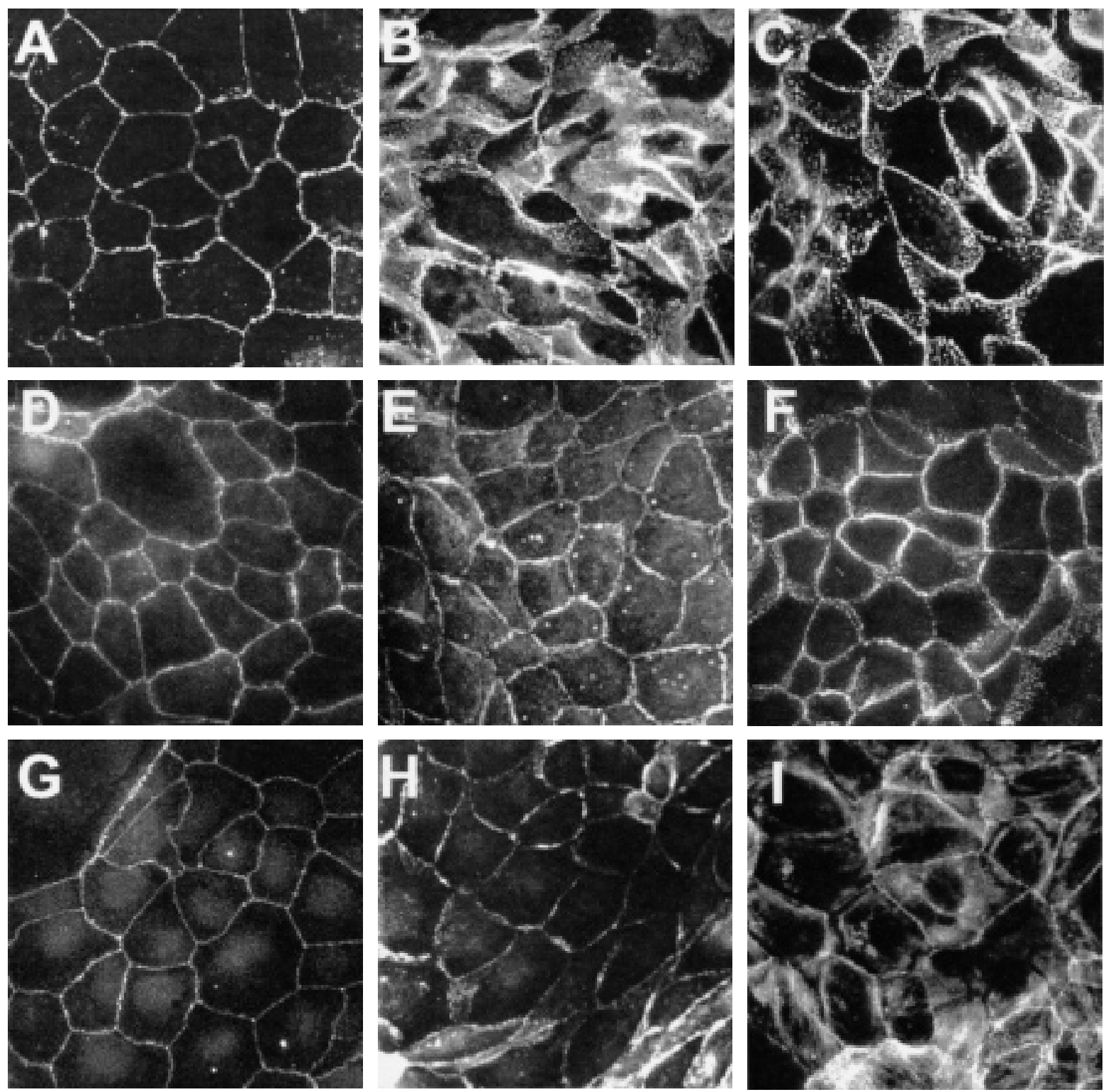

Fig. 3. - Fluorescent antibody staining of proteins associated with intercellular adhesions in the human airway epithelial cell line Calu-3 and their visualization by conventional epifluorescence microscopy. A-C: labelling patterns of occludin, E-cadherin and desmoplakin respectively, without CSK buffer. D-I) labelling of occludin, E-cadherin, desmoplakin, ZO-1, $\beta$-catenin and F-actin, respectively, in cells treated with CSK buffer prior to fixation and fluorescent antibody labelling.

desmoplakin revealed the presence of a punctate staining pattern typical of desmosomes (figs. 2C and 3C). A majority of the staining was associated with the cell periphery, although numerous puncta were evident within the cells. In both of the human airway cell lines the patterns of Ecadherin and desmoplakin immunostaining were similar to those seen in MDCK cells (not shown).

Comparison of figure $2 \mathrm{~A}$ with figure $2 \mathrm{D}$, and of figure $3 \mathrm{~A}$ with figure $3 \mathrm{D}$, shows that the majority of the occludin in both 16HBE14o- and Calu-3 cells appeared to be strongly associated with the cytoskeleton since the pattern of immunostaining was unchanged by detergent treatment of the cells prior to fixation. This confirms the expected strong association between functional TJs and the cytoskeleton. In contrast, comparison of figures $2 \mathrm{~B}$ and $\mathrm{D}$ with figures $2 \mathrm{E}$ and $\mathrm{F}$ shows also that in 16HBE14o- cells prefixation detergent treatment resulted in a decreased immunostaining of E-cadherin and, to a lesser extent, desmoplakin. The amounts of peripheral E-cadherin and desmoplakin immunostaining in Calu-3 cells were also decreased by prefixation exposure to detergent buffer (compare fig. 3C and F). The authors infer that these particular components of intercellular junctions in $16 \mathrm{H}-$ BE 14o- and Calu-3 cells are less well associated with the cytoskeleton than are the TJ proteins; the detergent extractable fraction perhaps representing E-cadherin and desmoplakin with mainly extrajunctional or cytoplasmic localization. Rhodamine-phalloidin staining of F-actin revealed the presence of perijunctional rings of $\mathrm{F}$-actin in both cell lines, together with a fine meshwork of cytoplasmic stress fibres orientated perpendicular to the apicobasal axis (figs. 2I and 3I). 
a)
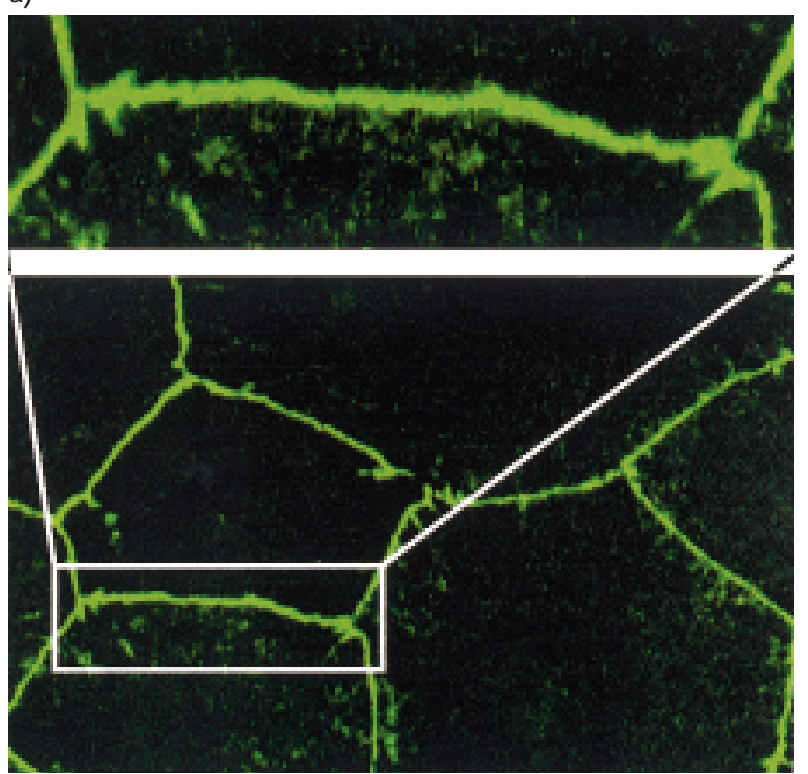

b)

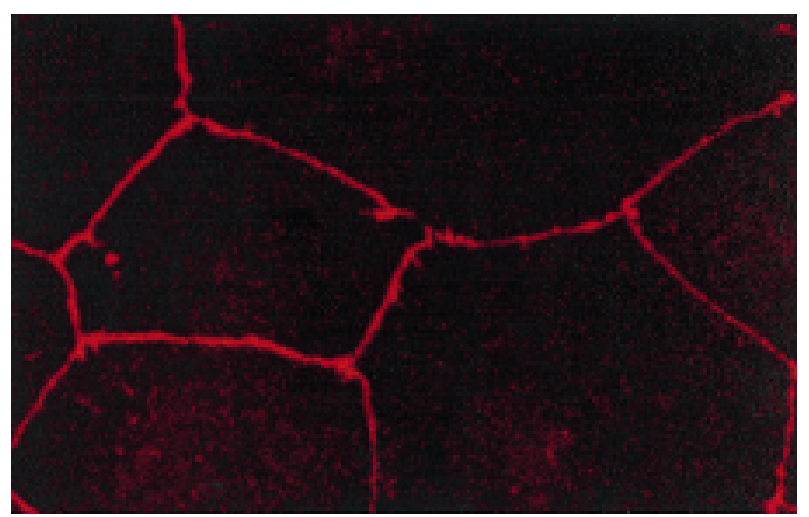

c)

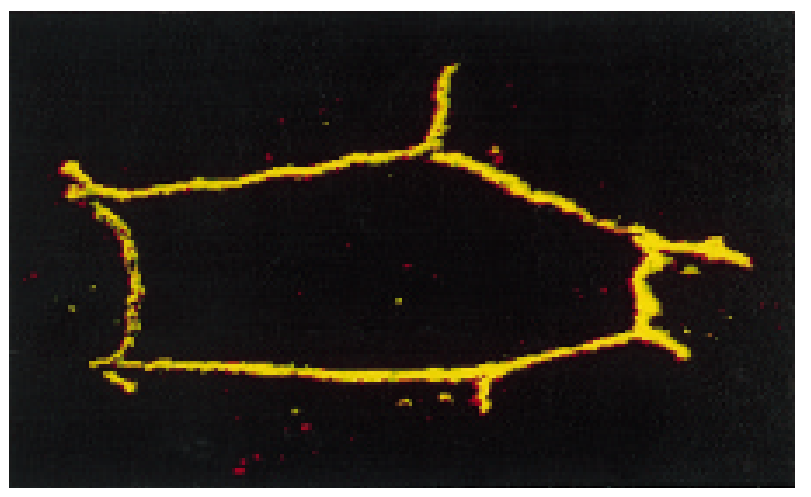

d)
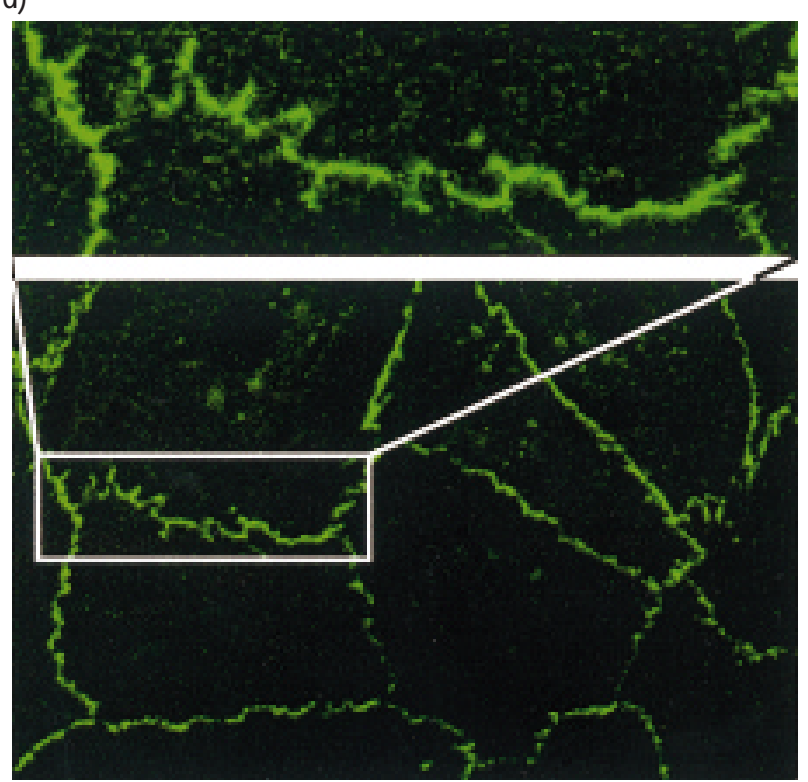

e)

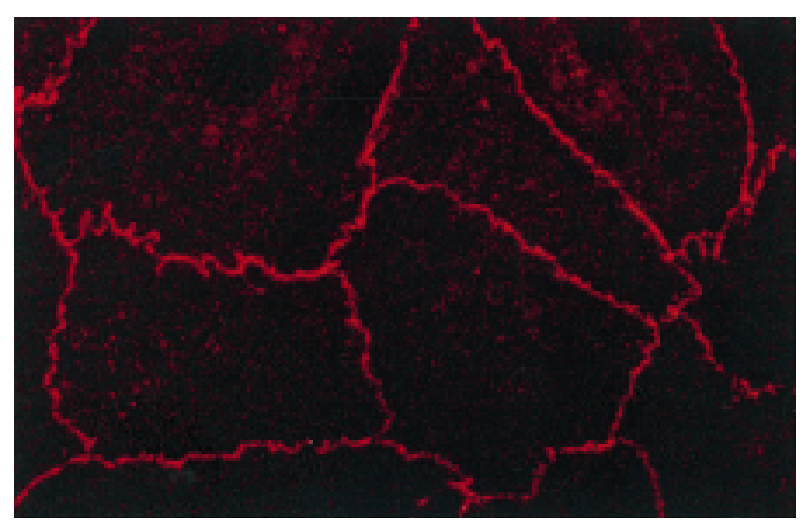

f)

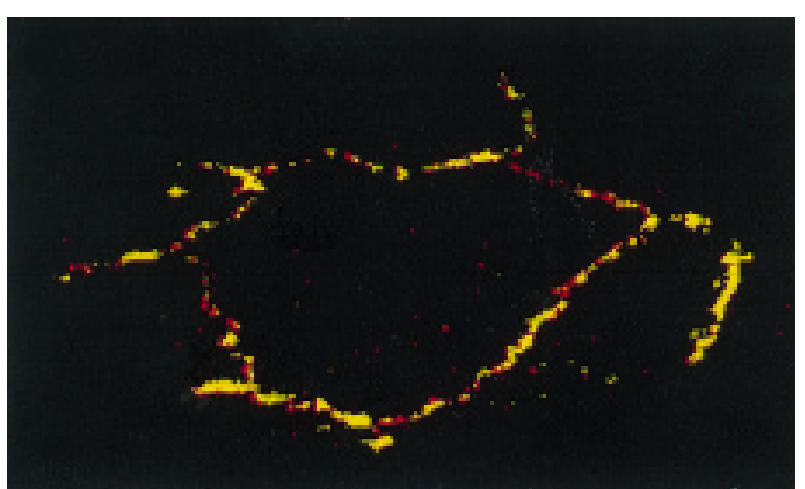

Fig. 4. - Relative distribution of the tight junction proteins occludin and ZO-1 in cultured human airway epithelial cells examined by fluorescent antibody labelling and 2-photon molecular excitation microscopy. a and b) Through-focus images depicting the labelling patterns of occuludin in $16 \mathrm{HBE} 14 \mathrm{o}-$ cells. c) The apparent colocalization of occludin and ZO-1 as a three-dimensional isosurface reconstruction of the image data. $\mathrm{d}-\mathrm{f}$ ) Show corresponding images obtained in Calu-3 cells. Note the zoom windows attached to a and d showing the difference in the appearance of the junctional margins of $16 \mathrm{HBE} 14 \mathrm{o}-$ and Calu-3 cells.

The distribution of occludin and ZO-1 was highly concordant in both of the epithelial cell lines derived from human airways. Figure 4 shows dual fluorescent antibody labelling of occludin (a and d) and ZO-1 (b and e) in the same populations of cells imaged by 2 PMEM. Since 2 - photon excitation spectra are wide and chromatic aberration is eliminated by this imaging technique, the use of 2PMEM allowed the authors to excite both fluorochromes simultaneously and to map their spatial localization with high accuracy. Superimposition of the digital 
a)

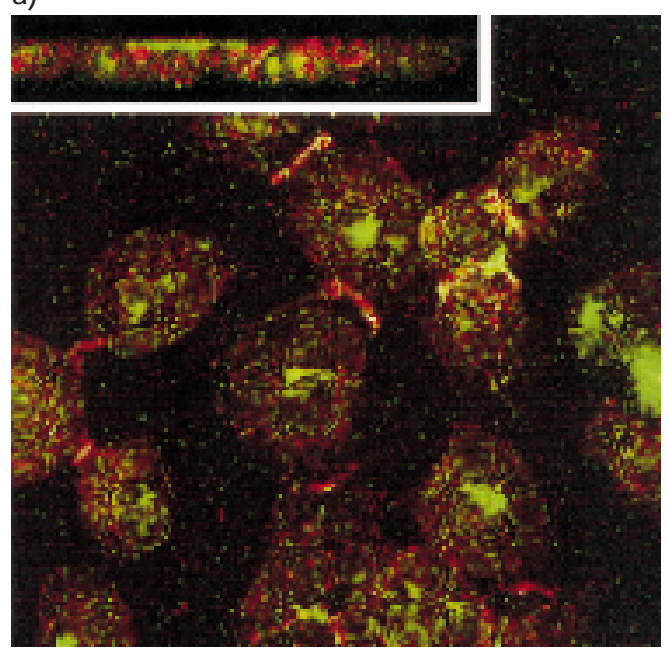

b)

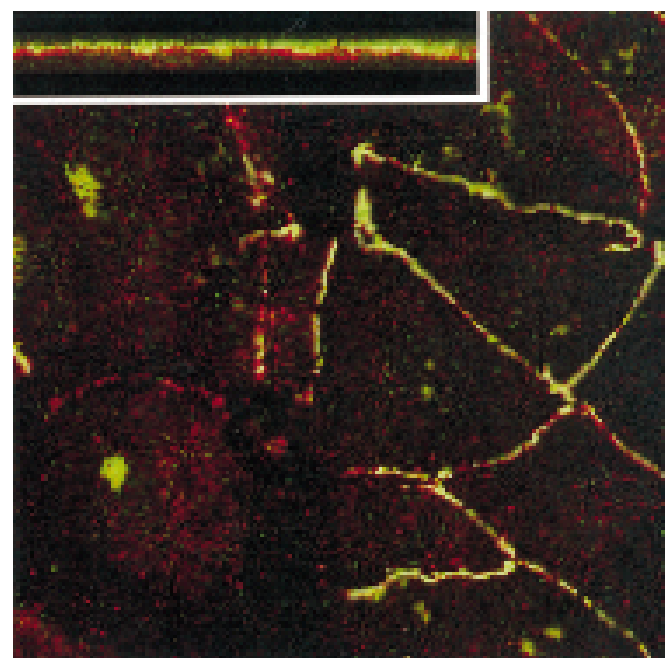

c)

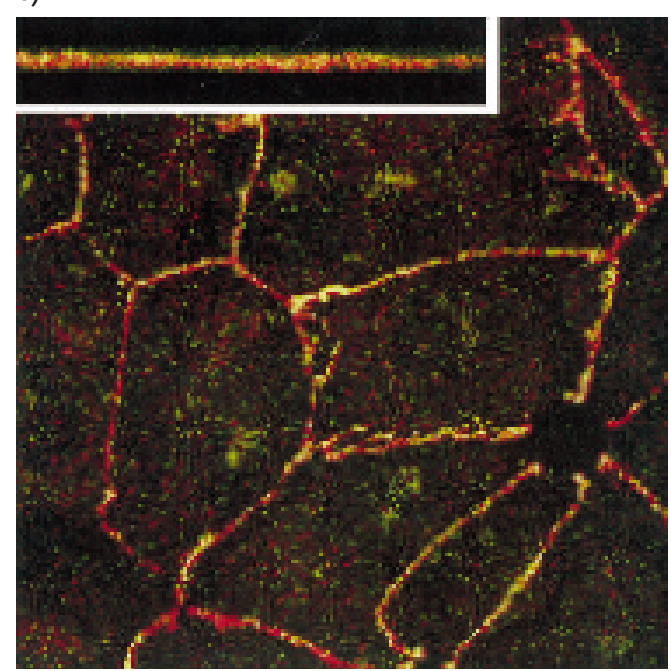

d)

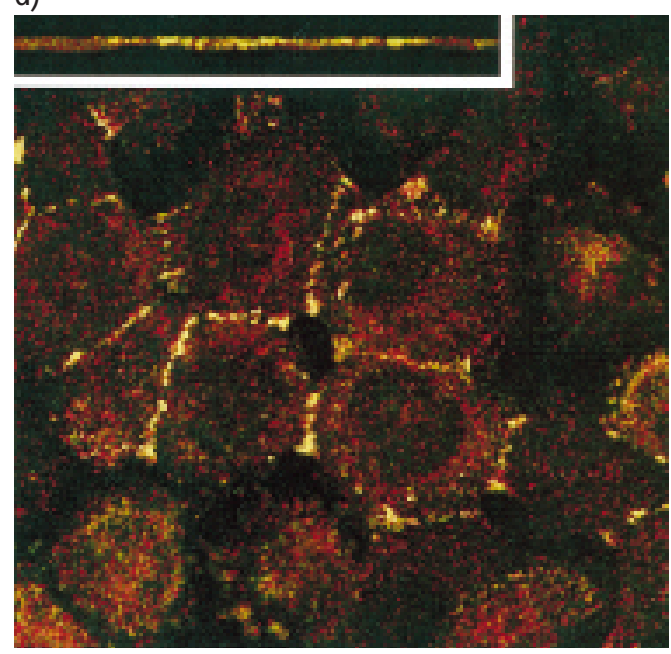

e)

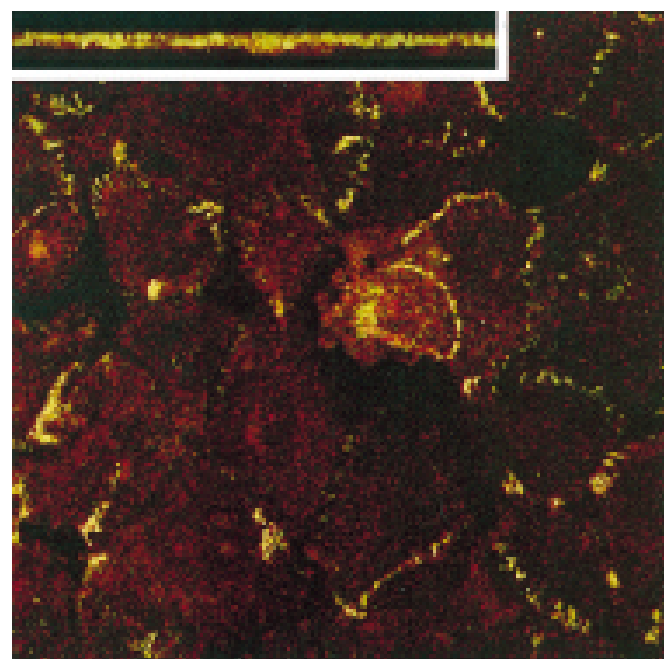

f)

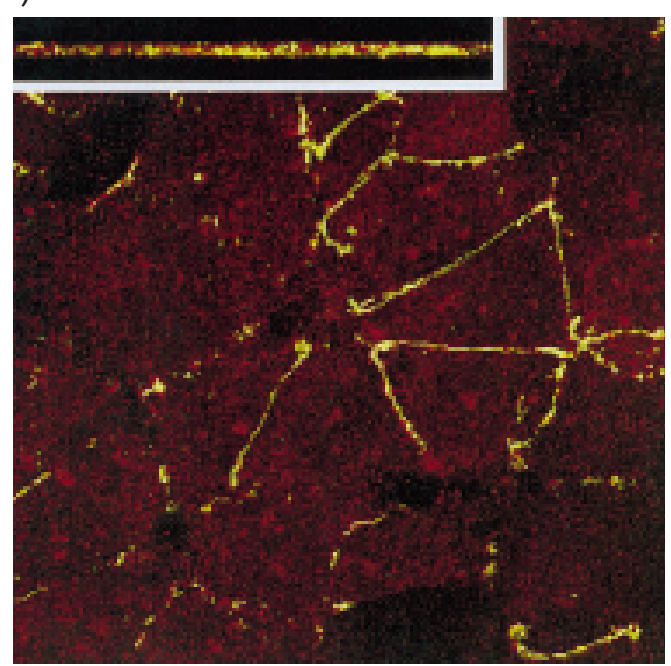

Fig. 5. - Effect of calcium "switch" on tight junction proteins in Cal-3 and 16HBE14o- cells. Cells were plated on to coverslips in $\mathrm{Ca}^{2+}$-replete culture medium and allowed to adhere for $5 \mathrm{~h}$ before adding fresh medium containing $5 \mathrm{mM}$ ethylene glycol tetra-acetic acid. On the third day after plating, the cells were washed and extracellular $\mathrm{Ca}^{2+}$ was restored to the culture medium. Individual coverslips were fixed at specific intervals after the $\mathrm{Ca}^{2+}$ switch and the presence of occludin (green labelling) and ZO-1 (red labelling) investigated by fluorescent antibody labelling and 2-photon molecular excitation microscopy imaging. Sites of colocalized occludin and ZO-1 appear yellow. Each major panel within the illustration shows an extended focus x-y image for the time points indicated. The inset in the upper left hand corner of each panel shows the corresponding $x-z$ image of the cells. a-c) Calu- 3 cells at 30 , 60 and $120 \mathrm{~min}$ from up switch to fixation, respectively. d-f) $16 \mathrm{HBE} 14 \mathrm{o}-$ cells at 60,120 and $300 \mathrm{~min}$ from up switch to fixation, respectively. 


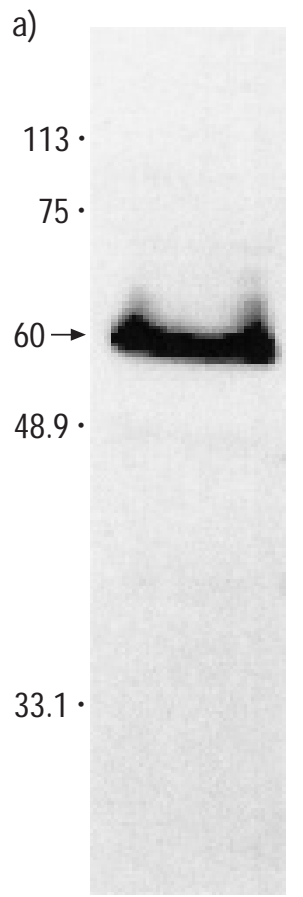

Occludin

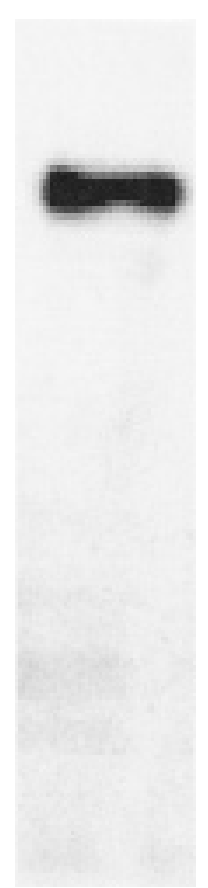

ZO-1 b)

113 .

75 .

$72 \rightarrow$

$66 \rightarrow$

$53 \rightarrow$

48.9 .

$43 \rightarrow$

$33.1 \cdot$

24.4 .

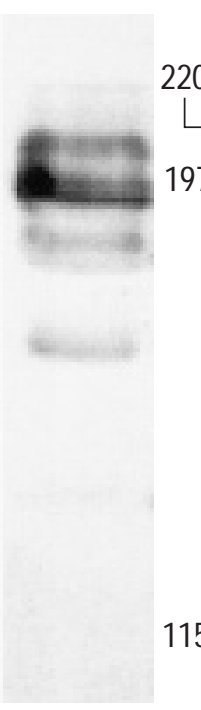

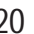

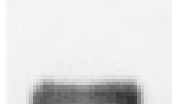

97 .

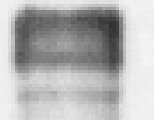

$115 \cdot$ c)

$\underset{83}{\stackrel{116}{9} \text {. }}$

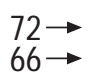

$72 \rightarrow$

$53 \rightarrow$

83 .

$43 \rightarrow$

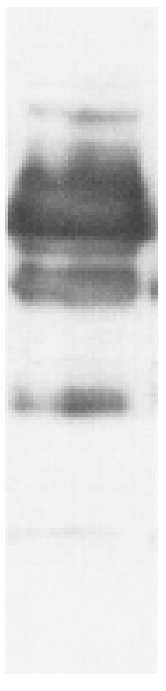

220

$\underset{203 \text {. }}{\longrightarrow}$

$116 \cdot$

33.4 .

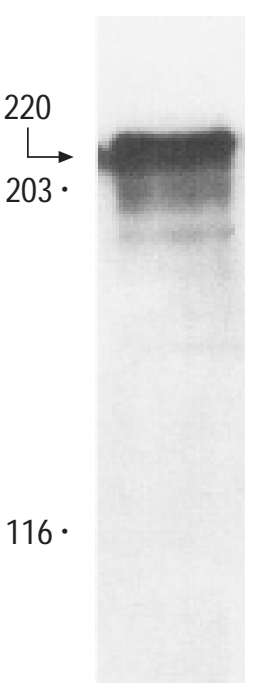

Occludin

ZO-1

ZO-1

Fig. 6. - Immunoblots of the tight junction proteins occludin and ZO-1 from Madin-Darby canine kidney (a), 16HBE14o- (b) and Calu-3 cells (c). The circles adjacent to each immunoblot show the migration of molecular weight markers. Arrows with numbers indicate the apparent molecular weights $(\mathrm{kDa})$ of major bands.

data sets encoding the fluorescent antibody labelling for each protein within a given monolayer produced images of TJ rings that are predominantly yellow with only a few areas of "dropout" where single colour (red or green) staining is visible (fig. $4 \mathrm{c}$ and $\mathrm{f}$ ). This suggests that within the resolution achievable by 2 PMEM the two TJ proteins are spatially colocalized at TJs. However, it is also clear from figure 4 that there are some differences in the fine structure of the TJ rings in these cell types. The zoom windows in figures $4 \mathrm{a}$ and $\mathrm{d}$ show that the junctional margins of Calu-3 cells differed from those of 16HBE14o- cells in being more tortuous and interdigitated. The greater tortuosity of TJs in Calu-3 cells was evident with both occludin and ZO-1 labelling (fig. 4). The more tortuous cell boundaries formed in monolayers of Calu-3 cells were reproducible features which distinguished the TJs of this epithelial cell line from the less interdigitated patterns seen in MDCK cells (not shown) and in 16HBE14o- cells (fig. 4a-e). Inspection of the 2PMEM image data suggested that in addition to their more tortuous appearance the occludin rings of Calu-3 cells also contained more obvious breaks in their staining pattern than did 16HBE14o- cells. This impression was supported by comparing the discontinuities in staining profile in overlaid patterns of occludin and ZO-1 1abelling for the two cell lines (fig. $4 \mathrm{c}$ and $\mathrm{f}$ ) and by measuring the extent of these breaks. Quantification of the 2PMEM images revealed that in the occludin rings of Calu- 3 cells there were on average $20.8 \pm 1.0$ breaks per TJ ring compared with $1.5 \pm 0.9$ in $16 \mathrm{HBE} 14 \mathrm{o}$ - cells $(\mathrm{n}=4, \mathrm{p}<0.05)$. However, the average length of TJ breakage was similar in the two cell lines: $3.8 \pm 0.2$ and $3.5 \pm 1.2 \mu \mathrm{m} \cdot \mathrm{cell}^{-1}$ respectively.
Further evidence that $16 \mathrm{HBE} 140-$ and Calu- 3 cells possess modulatable TJs consisting of closely apposed occludin and ZO-1 was provided by observing the responses of the cells to a $\mathrm{Ca}^{2+}$ "switch" (fig. 5). Depletion of extracellular calcium using EGTA caused loss of the occludin and $\mathrm{ZO}-1$ rings, but these were gradually rebuilt from both proteins following restitution of extracellular $\mathrm{Ca}^{2+}$ (fig. 5).

Figure 6 shows Western blots of the TJ proteins occludin and ZO-1 from the three cell lines examined in this study. Occludin and ZO-1 of MDCK cells immunoblotted essentially as single bands of apparent molecular masses $60 \mathrm{kDa}$ and $220 \mathrm{kDa}$ respectively (fig. 6a). By comparison, the immunoblotting profiles of these proteins in 16HBE14o- and Calu-3 cells were more complex. Occludin was detected as a major band with an apparent mass of $62-66 \mathrm{kDa}$ that was associated with less prominent bands at $43-45 \mathrm{kDa}, 52-57 \mathrm{kDa}$ and $72-74 \mathrm{kDa}$ (fig. $6 \mathrm{~b}$ and c). In addition, an immunoreactive $94 \mathrm{kDa}$ band was detected in Calu-3 cells. In the human cell lines, the TJ plaque protein ZO-1 was detected as a major product at $\sim 220 \mathrm{kDa}$, with minor bands of $\sim 190 \mathrm{kDa}$ also detectable.

\section{Discussion}

Alterations in the plasticity of TJs, or their outright cleavage, have been suggested to be significant potentially pathophysiological events in the airways epithelium [1, 25]. Progress towards understanding the mechanisms involved have been impeded by the absence of wellcharacterized cellular models. In this study the authors 
describe details of the intercellular junctions of $16 \mathrm{H}-$ BE14o- and Calu-3 epithelial cell lines which make them potentially useful tools for the study of TJ biogenesis, regulation and breakdown.

Both 16HBE140- and Calu-3 cell lines expressed desmosomes, adherens junctions and functional TJs. The formation of confluent monolayers of cells expressing contiguous TJs was associated with the development of an increasing TER. The gradual decline in TER following attainment of a peak value is consistent with previous studies in MDCK cells [26]. This decrease in TER probably occurs because as the numbers of cells packed within the monolayer increases the total length of cell perimeters per unit area of monolayer also increases. Since the TER developed by an epithelial monolayer is determined to a large degree by the nature of its cell boundaries, an increase in the length of the cell perimeter per unit area should lead to a decrease in TER. This concept has been supported experimentally in growtharrested cells which show no decrease in TER as monolayers age despite the properties of the TJs being similar to those in dividing cell monolayers [27]. Consistent with the development of effective occluding junctions, monolayers of 16HBE14o- or Calu-3 cells were found to develop a low permeability to the cell impermeant sugar, mannitol [28].

Imaging of the cells after fluorescent antibody labelling of occludin and ZO-1 confirmed that 16HBE14o- and Calu-3 cells formed TJ "rings". By using 2PMEM, which suffers from only minimal chromatic aberration and which allows simultaneous excitation of multiple fluorochromes, the authors were able to provide morphological evidence in support of the suspected close association between these proteins. Previously, the morphological association between occludin and ZO-1 has been inferred from images obtained by nonconfocal or single photon confocal microscopy in which testing for colocalization can be problematic [9, 29].

The morphology of the TJ rings in 16HBE14o- cells, was similar to that in the extensively studied MDCK epithelial cell line. In contrast, the cell boundaries of Calu3 cells were more tortuous and had a greater incidence of breaks in the TJ labelling patterns. The irregularity of TJs in Calu-3 cells might arise because the membrane surface topology of these cells is less homogenous than in $16 \mathrm{HBE} 14 \mathrm{o}-$ cells. Alternatively, the irregularities might represent the formation of aberrant $\mathrm{TJ}$ strands or fascia occludens. Although the TJs of Calu-3 cells exhibited a significantly greater number of breaks in their $\mathrm{TJ}$ rings than 16HBE14o- cells, mannitol permeability coefficients were similar in the two cell lines. This potential paradox is explained by the aggregate break length being similar in the two cell lines; the gaps in the TJs of Calu-3 cells were numerous and of short distance, whereas gaps in $16 \mathrm{H}-$ BE14o- cell TJs were individually longer in length but fewer in number. This raises the issue of whether a gap in the labelling of a TJ protein is necessarily indicative of an incomplete or dysfunctional TJ. The recent discovery of claudins $[30,31]$ and the immunoglobulin superfamily member junctional adhesion molecule (JAM) [32] as additional transmembrane proteins of TJs suggests that TJ integrity is probably maintained by complex interactions between multiple adhesion proteins. Thus, it may be possible for some TJ adhesion proteins to have minor discontinuities in their staining pattern without barrier function being impaired. This underscores the need to complement morphological techniques with tests of function when exploring the role of the epithelial barrier in pathophysiological events.

Immunoblotting demonstrated that the TJ protein occludin was detectable at a range of molecular masses in both cell lines from human airways epithelium. The most abundant of the forms had an apparent molecular mass of 62-66 $\mathrm{kDa}$, close to the predicted molecular mass of the unmodified protein. Recent studies have suggested that occludin may undergo function-dependent modifications and that it may be the "heavy", possibly phosphorylated, forms of occludin that seal TJs [33, 34]. The human airway cell lines expressed heavy forms of occludin (bands of 72-74 kDa were detectable in both cell lines with a protein of $94 \mathrm{kDa}$ additionally present in Calu-3 cells), although the authors are unable to comment on their phosphorylation status. Weak bands at $43-45 \mathrm{kDa}$ and $52-57 \mathrm{kDa}$ found in occludin immunoblots may be proteolytic fragments formed during protein extraction. In contrast, occludin from MDCK cells showed less heterogeneity than its human counterparts. However, as the authors were not able to blot canine and human occludin with the same antibody because of a lack of species crossreactivity, caution should be exercised in interpreting the possible meaning of this difference. All three cell lines expressed broad bands of ZO-1 immunostaining with apparent molecular masses of $\sim 220 \mathrm{kDa}$. The broad bands of ZO-1 in immunoblots of all three cell types is consistent with some heterogeneity in this protein, either because of differential phosphorylation or due to the presence of ZO-1 isoforms [35]. The human airway cell lines had additional weak bands detectable by immunoblotting. It is likely that these weak bands arise by proteolysis since the authors have detected similar bands in cells explicitly treated with proteinases prior to immunoblotting [25]. Whilst the possibility that the proteinase inhibitors failed to provide adequate inhibition of $\mathrm{TJ}$ protein proteolysis during the preparation of cell extracts cannot be excluded, the high prevalence of breakdown products in Calu- 3 cells may be indicative of a continuous turnover of TJ proteins in this cell line. This would offer a further explanation of the relatively high incidence of breaks in the continuity of TJ rings in these cells.

Calu-3 and 16HBE14o- cells offer the potential to be useful models for cell biological investigations of airway epithelial cell functions. Previous work has demonstrated that Calu-3 cells can express tight junctions, secretory component, secretory leukocyte proteinase inhibitor, lysozyme, lactoferrin, and the MUC-2 mucin gene, demonstrate constitutive and phorbol 12-myristate 13-acetate-inducible gelatinase $\mathrm{B}$ activity, have an active cystic fibrosis transmembrane conductance regulator and display functional cyclic adenosine monophosphate-dependent chloride secretion [18, 36-38]. 16HBE14o- cells possess tight junctions, cystic fibrosis transmembrane conductance regulator and functional chloride conductances [19], they express functional $\beta$-adrenoceptors [39], and the cytokines interleukin-2 [40], and interleukin-8 [39], utilize the transcription factor nuclear factor- $\kappa \mathrm{B}$ [41] and contain type-III phosphodiesterase [42]. Taken together with the evidence from other investigations [25], these data collectively suggest that the 16HBE14o- and Calu-3 epithelial cell lines 
may prove to be useful paradigms of the permeability functions of human airway epithelium, especially in studies of tight junction assembly and disassembly.

\section{References}

1. Robinson C. The airway epithelium: the origin and target of inflammatory airways disease and injury. In: Holgate ST, ed. Immunopharmacology of the Respiratory System. London, UK, Academic Press, 1995; pp. 187-207.

2. Pabst R, Binns RM. Lymphocytes migrate from the bronchoalveolar space to regional bronchial lymph nodes. Am J Respir Crit Care Med 1995; 151: 495-499.

3. Anderson JM, Van Itallie CM. Tight junctions and the molecular basis for regulation of paracellular permeability. Am J Physiol 1995; 269: G467-G475.

4. Schneeberger EE, Lynch RD. Structure, function and regulation of cellular tight junctions. Am J Physiol 1992; 262: L647-L661.

5. Keon BH, Schafer S, Kuhn C, Grund C, Franke WW. Symplekin. A novel type of tight junction plaque protein. J Cell Biol 1996; 134: 1003-1018.

6. Yarnamoto T, Harada N, Kano K, et al. The Ras target AF-6 interacts with ZO-1 and serves as a peripheral component of tight junctions in epithelial cells. J Cell Biol 1997; 139: 785-795.

7. Haskins J, Gu L, Wittchen ES, Hibbard J, Stevenson BR. ZO-3, a novel member of the MAGUK protein family found at the tight junction interacts with ZO-1 and occludin. J Cell Biol 1998; 141: 199-208.

8. Ando-Akatsuka Y, Saitou M, Hirase T, et al. Interspecies diversity of the occludin sequence: cDNA cloning of human, mouse, dog and rat-kangaroo homologues. $J$ Cell Biol 1996; 133: 43-47.

9. Furuse M, Hirase $\mathrm{T}$, Itoh $\mathrm{M}$, et al. Occludin: a novel integral membrane protein localizing at tight junctions. $J$ Cell Biol 1993; 123: 1777-1788.

10. Wong V, Gumbiner BM. A synthetic peptide corresponding to the extracellular domain of occludin perturbs the tight junction permeability barrier. J Cell Biol 1997; 136: 399-409.

11. Stevenson BR. Understanding tight junction clinical physiology at the molecular level. J Clin Invest 1999; 104: 34.

12. Robinson C, Kalsheker NA, Srinivasan N, et al. On the potential significance of the enzymatic activity of mite allergens to immunogenicity. Clues to structure and function revealed by molecular characterization. Clin Exp Allergy 1997; 27: 10-21.

13. Herbert CA, King CM, Ring PC, et al. Augmentation of permeability in the bronchial epithelium by the house dust mite allergen Der p 1. Am J Respir Cell Mol Biol 1995; 12: 369-378.

14. Herbert CA, Edwards D, Boot JR, Robinson C. In vitro modulation of the eosinophil-dependent enhancement of the permeability of the bronchial mucosa. Br J Pharmacol 1991; 104: 391-398.

15. Herbert CA, Arthur MJP, Robinson C. Eosinophils augment gelatinase activity in the airway mucosa. Comparative effects as a putative mediator of epithelial injury. $\mathrm{Br}$ J Pharmacol 1996; 117: 667-674.

16. Winton HL, Wan H, Cannell MB, et al. Cell lines of pulmonary and non-pulmonary origin as tools to study the effects of house dust mite proteinases on the regulation of epithelial permeability. Clin Exp Allergy 1998; 28: 12731285.
17. Cozens AL, Yezzi MJ, Kunzelmann $\mathrm{K}$, et al. CFTR expression and chloride secretion in polarized immortal human bronchial epithelial cells. Am J Respir Cell Mol Biol 1994; 10: 38-47.

18. Finkbeiner WE, Carrier SD, Teresi CE. Reverse transcription-polymerase chain reaction (RT-PCR) phenotypic analysis of cell cultures from human tracheal epithelium, tracheobronchial glands and lung carcinomas. Am J Respir Cell Mol Biol 1993; 9: 547-556.

19. Winton $\mathrm{BL}$, Wan $\mathrm{H}$, Cannell $\mathrm{MB}$, et al. Class specific inhibition of house dust mite proteinases which cleave cell adhesion, induce cell death and which increase the permeability of lung epithelium. Br J Pharmacol 1998; 124: 1048-1059.

20. Saltou M, Ando-Akatsuka Y, Itoh M, et al. Mammalian, occludin in epithelial cells: its expression and subcellular distribution. Eur J Cell Biol 1997; 73: 222-231.

21. Vestweber D, Kernler R. Identification of a putative cell adhesion domain of uvomorulin. EMBOJ 1985; 4: 33933398.

22. Parrish EP, Steart PV, Garrod DR, Weller RO. Antidesmosomal monoclonal antibody in the diagnosis of intracranial tumours. J Pathol 1987; 153: 265-273.

23. Stevenson BR, Goodenough D. Zonula occludentes in junctional-complex-enriched fractions from mouse liver: preliminary morphological and biochemical characterization. J Cell Biol 1984; 98: 1209-1221.

24. Soeller C, Cannell MB. Construction of a two-photon microscope and optimisation of illumination pulse duration. Pflügers Arch-Eur J Physiol 1996; 432: 555561.

25. Wan H, Winton BL, Soeller C, et al. Der $p 1$ facilitates transepithelial allergen delivery by disruption of tight junctions. J Clin Invest 1999; 104: 123-133.

26. Cereijido M, Gonzàlez-Mariscal L, Borboa L. Occluding junctions and paracellular pathways studied in monolayers of MDCK cells. J Exp Biol 1983; 106: 205-215.

27. Rabito CA. Reassembly of the occluding junction in a renal cell line (LLC-PK1) with characteristics of proximal tubular cells. Am J Physiol 1986; 251: F978-F987.

28. Dawson DC. Na and $\mathrm{Cl}$ transport across the isolated turtle colon: parallel pathways for transmural ion movement. $J$ Membr Biol 1977; 37: 213-233.

29. Furuse $\mathrm{M}$, Itoh $\mathrm{M}$, Hirase $\mathrm{T}$, et al. Direct association between occludin and ZO-1 and its possible involvement in the localization of occludin at tight junctions. $J$ Cell Biol 1994; 127: 1617-1626.

30. Furuse M, Fujita K, Hiiragi T, Fujimoto K, Tsukita S. Claudin-1 and -2: novel integral membrane proteins localizing at tight junctions with no sequence similarity to occludin. J Cell Biol 1998; 141: 1539-1550.

31. Morita S, Furuse M, Fujimoto K, Tsukita S. Claudin multigene family encoding four-transmembrane domain protein components of tight junction strands. Proc Natl Acad Sci US A 1999; 96: 511-516.

32. Martin-Padura I, Lostaglio S, Schneeman $\mathrm{M}$, et al. Junctional adhesion molecule, a novel member of the immunoglobulin superfamily that distributes at intercellular junctions and modulates monocyte transmigration. $J$ Cell Biol 1998; 142: 117-127.

33. Sakakibara A, Furuse M, Saitou M, Ando-Akatsuka Y, Tsukita S. Possible involvement of phosphorylation of occludin in tight junction formation. J Cell Biol 1997; 137: 1393-1401.

34. Wong V. Phosphorylation of occludin correlates with occludin localization and function at the tight junction. Am J Physiol 1997; 273: C1859-C1867. 
35. Balda MS, Anderson M. Two classes of tight junctions are revealed by ZO-1 isoforms. Am J Physiol 1993; 264: C918-C924.

36. Shen BQ, Finkbeiner WE, Wine JJ, Mrsny RJ, Widdicombe JH. Calu-3: a human airway epithelial cell line that shows cAMP-dependent $\mathrm{Cl}^{-}$secretion. Am $J$ Physiol 1994; 269: L493-L501.

37. Haws C, Finkbeiner WE, Widdicombe JH, Wine JJ. CFTR in Calu-3 human airway cells: channel properties and role in cAMP-activated $\mathrm{Cl}^{-}$conductance. $\mathrm{Am} \mathrm{J}$ Physiol 1994; 266: L502-L512.

38. Carver JE, Galloway A, Robinson C. Inhibition of gelatinase activity in human airway epithelial cells and fibroblasts by dexamethasone and beclomethasone. $\mathrm{Br} J$ Pharmacol 1999; 127: 1119-1128.
39. Linden A. Increased interleukin-8 release by beta-adrenoceptor activation in human transformed bronchial epithelial cells. Br J Pharmacol 1996; 119: 402-406.

40. Aoki Y, Qiu D, Uyei A, Kao PN. Human airway epithelial cells express interleukin-2 in vitro. Am J Physiol 1997; 272: L276-L286.

41. Aoki Y, Kao PN. Cyclosporin A-sensitive calcium signaling represses $\mathrm{NF \kappa B}$ activation in human bronchial epithelial cells and enhances NFKB activation in Jurkat T-cells. Biochim Biophys Res Commun 1997; 234: 424431.

42. Kelley TJ, al-Nakkash L, Drumm ML. CFTR-mediated chloride permeability is regulated by type III phosphodiesterases in airway epithelial cells. Am J Respir Cell Mol Biol 1995; 13: 657-664. 